\title{
Analysis of CTLA-4 -318C/T Polymorphism in Thalassemia Patients Transfused at the Casablanca Children's Hospital (Morocco)
}

\author{
Samira El Kababi, Bouchra El Khalfi, Khadija El Maaani, and Abdelaziz Soukri
}

\section{ABSTRACT}

Red blood cells (RBC) alloimmunization is a delayed adverse transfusion reaction in thalassemia patients. The mechanisms behind the inhibition or tolerance of red blood cells are still poorly understood. Cytotoxic Tlymphocyte-associated antigen 4 (CTLA-4) molecule is expressed on Treg lymphocyte membrane and is an inhibitory molecule which plays the mediator role of peripheral tolerance and maintains tolerance to selfantigens. Recent studies have reported that defect in the CTLA-4 gene expression could affect its function and be involved in the development of various pathologies as autoimmune diseases and the outcome after Allogenic hematopoietic stem cell transplantation; indeed, the objective of our study is the search for the association of the CTLA-4 polymorphism with the susceptibility to red blood cells alloimmunizations. In this study we looked for the polymorphism of the CTLA-4 gene at the $-318 \mathrm{C} / \mathrm{T}$ position in $35 \beta$-thalassemic patients (15alloimmunized and 20 non alloimunized) followed at the children's hospital in Casablanca, and 20 healthy controls, by PCR-RFLP and Sanger sequencing. In our cohort, none of the group cases revealed the mutation carried out by PCR RFLP. Indeed, this result was confirmed by Sanger sequencing. This study does not find an association of $-318 C$ /T SNPs in CTLA-4 gene and RBC alloimmunization among our cohort. Following these preliminary results, an investigation of the other exons of the CTLA-4 gene on a large cohort is necessary to complete this study.

Keywords: Red blood cells alloimmunizations, CTLA-4, thalassemia, polymorphism.

Submitted: September 8, 2021

Published: September 30, 2021

ISSN: 2593-8339

DOI: $10.24018 /$ ejmed.2021.3.5.1054

\section{S. El Kababi*}

Laboratory of Pathophysiology, Molecular Genetics and Biotechnology, Faculty of Science Ain Chock, Hassan 2 University, Casablanca Higher Institute of Nursing and Health Techniques, Casablanca, Morocco.

(e-mail: samira.elkababi@gmail.com) B. El Khalfi

Laboratory of Pathophysiology, Molecular Genetics and Biotechnology, Faculty of Science Ain Chock, Hassan 2 University, Casablanca, Morocco.

(e-mail: bouchra.elkhalfi@gmail.com) K. El Maani

Hematology-Oncology Pediatric department, Children's Hospital, Faculty of Medicine, Hassan 2 University, Casablanca, Morocco.

(e-mail: elmaani@hotamail.com)

A. Soukri

Laboratory of Pathophysiology,

Molecular Genetics and Biotechnology, Faculty of Science Ain Chock, Hassan 2 University, Casablanca, Morocco.

(e-mail: a_soukri@hotamail.com)

*Corresponding Author

\section{INTRODUCTION}

The transfusion therapy remains the conventional and essential treatment for thalassemia patients to this day [1], [2]. However It is confronted to RBC alloimmunizations challenge by erythrocyte phenotypic missmatched between donors and recipients [3]-[6] leading to delayed transfusion hemolysis and difficulties to finding compatible units leading to a transfusion deadlock [7]. On the other hand, the alloimmunization can affect the outcomes after allogeneic hematopoietic stem cell transplants (HSCT) and increase the transplant rejection risk [8].

Although extensive phenotyping of RBCs have minimized the sensibilisation against erythrocytes [3], [9] genetic or immunological markers that differentiate a "responder" from "non-responder" to erythrocyte antigens remains undefined, although tolerance to erythrocyte antigens has been reported in a murine alloimmunization model [10].

The identification of regulatory $\mathrm{T}$ lymphocytes (Tregs) among the CD4 $+\mathrm{CD} 25+\mathrm{T}$ cell subset as a key regulators of peripheral tolerance in mice as well as in humans has ushered in an exciting era in prevention and treatment of autoimmune diseases and for the improvement of organ transplantation [11]. However, their potential to induce transfusion tolerance remains to be explored.

One of the Treg-mediated suppression mechanisms involves the CTLA-4 (or CD152) antigen, a molecule newly described in the early 2000 years [12]. It's a member of the immunoglobulin superfamily and is a $\mathrm{T}$ cell activation negative regulator. which shares the same ligands (CD80 and 
CD86) as CD28 but exerts inhibitory functions on the activation and proliferation of activated CD4 + lymphocytes (LT), and indeed represents an important regulator of immunotolerance [7]. In fact, any modification of the CTLA4 expression will affect its inhibitory action which will result in immunotolerance disorders. As such, it has been reported by several studies that genetic polymorphisms modifying the expression of CLTA-4, mainly 49A / G and $-318 \mathrm{C} / \mathrm{T}$, have been associated with an increased risk of autoimmune diseases [13],

[14], complications after allogeneic hematopoietic stem cell transplantation (HSCT) and rejections allografts [15] which are physio pathologically similar to alloimmunizations against erythrocytes.

However, to our knowledge, there is no reference in the literature on the role of variants of the CTLA- 4 gene in the susceptibility to post-transfusion alloimmunization in homozygous beta-thalassemia patients. Indeed, our study is the first to explore the association of rs5742909 (-318C / T) SNPs with the occurrence of post-transfusion alloimmunization among thalassemia patients in Morocco.

\section{Patients And Methods}

\section{A. Patients}

The study was conducted on 35 homozygous thalassemia patients regularly transfused and followed in the Pediatric Onco-Hematology department of Casablanca's University Hospital Center (CUHC). The patients were clinically subdivided into 15 patients who have developed a post transfusion alloimmunizations (mean age $12.27 \pm 2.57$ years) and 20 not alloimmunized patients after at least three separate occasions (mean age $10.31 \pm 4.38$ years). the latter criterion is applied to ensure that these patients do not develop a post transfusion immunization. Patients diagnosed with autoimmune conditions were excluded from this study. Informed consent approved by the Scientific Research Ethics Committee of CHU IBN ROCHD in Casablanca and the National Commission for the Protection of Personal Data (CNDP) in Rabat (Authorization No: A-RS197), was read and signed by all patients or by their parents or legal guardians.

\section{B. Genetics Analysis}

DNA was extracted from $300 \mu$ l of whole blood already stored in the freezer at $-20{ }^{\circ} \mathrm{C}$ and thawed at room temperature. DNA extraction was carried after sample pretreatment using commercial Kits "PROMEGA Kit" and according to manufacturer's instruction.

Genotypes for $-318 \mathrm{C} / \mathrm{T}$ polymorphisms in CTLA-4 gene were determined by PCR RFLP and confirmed by Sanger sequencing. For each sample, $100 \mathrm{ng}$ of DNA was amplified by polymerase chain reaction (PCR) using specific primers (10uM) (Table I). The amplified products were purified using ExoSAP-IT PCR cleanup Kit (Applied Biosystems). PCR conditions were as follows: 2 min at $95{ }^{\circ} \mathrm{C}, 35$ cycles of $30 \mathrm{~s}$ at $95{ }^{\circ} \mathrm{C}, 30 \mathrm{~s}$ at $58^{\circ} \mathrm{C}$ and $30 \mathrm{~s}$ at $72^{\circ} \mathrm{C}$, followed by $3 \mathrm{~min}$ at $72^{\circ} \mathrm{C}$. RFLP analysis was carried out with $25 \mu$ reaction volume containing $10 \mu \mathrm{l}$ of PCR product and $1 \mu \mathrm{l}$ of the specific restriction enzymes $M s e I$.

sequence reactions were performed by using a Big Dye terminator cycle sequencing kit version 3.1 (Applied Biosystems). The optimal thermocycling conditions for the cycle sequencing reaction were as follows: 25 cycles of $96^{\circ} \mathrm{C}$ for $1 \mathrm{~min}, 96^{\circ} \mathrm{C}$ for $10 \mathrm{~s}, 50^{\circ} \mathrm{C}$ for $5 \mathrm{~s}$, and $60^{\circ} \mathrm{C}$ for $4 \mathrm{~min}$, followed by a $4{ }^{\circ} \mathrm{C}$ infinite hold. Sequencing products were purified by using BigDye ${ }^{\circledR}$ XTerminator ${ }^{\mathrm{TM}}$ Purification Kit (Applied Biosystems) and loaded onto an ABI 3130xL capillary sequencer (Applied Biosystems) according to the manufacturer's instructions.

\section{RESULTS}

\section{A. Patients' Characteristics}

In the present study, 35 patients with thalassemia major and 20 healthy controls were genotyped for the $-318 \mathrm{C} / \mathrm{T}$ (rs5742909) polymorphism of the CTLA-4 gene. Among the thalassemia patients 15 were alloimmunized (mean age: $12.27 \pm 2.5$ years) and 20 were non alloimmunized (mean age: $10.31 \pm 4.38$ years). The mean age in the healthy group was $13 \pm 11$ years.

\section{B. Restriction Fragment Length Polymorphism Products}

PCR products were evaluated by electrophoresis on $1.5 \%$ agarose gel in the presence of $100 \mathrm{bp}$ molecular weight marker (Promega) and visualized by the GBox photo documentation system (Fig. 1). After digestion, the electrophoretic profile of the digested products showed fragments undigested which indicates the absence of the mutated allele $\mathrm{T}$ within the groups.

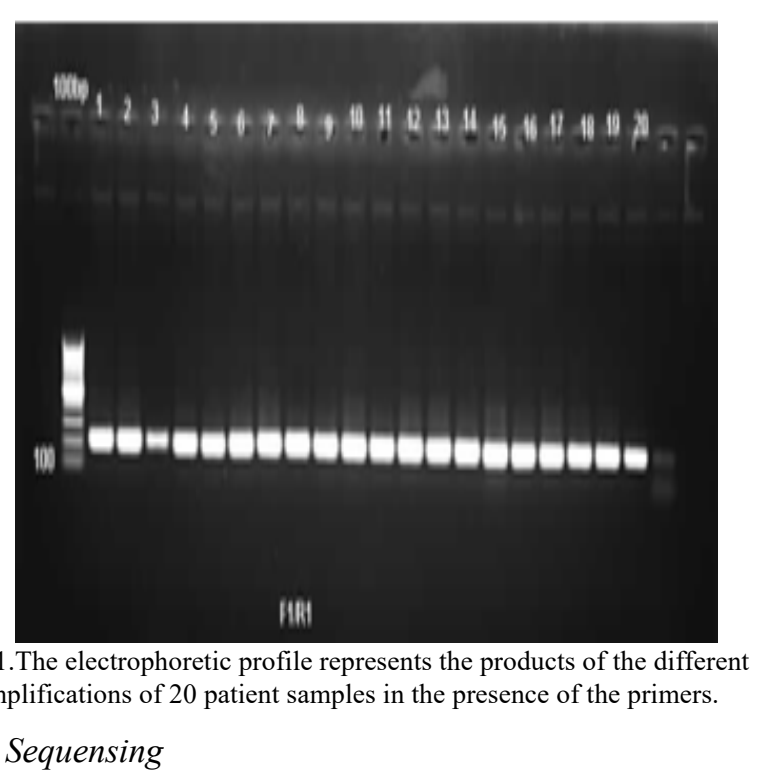

The sequencing of CTLA4 gene is taken from NCBI sequence website. CTLA4 gene locus in chromosome 2 from 4986-11180 bp. Partially sequence of CTLA4 gene as illustrated in (Fig. 2). 


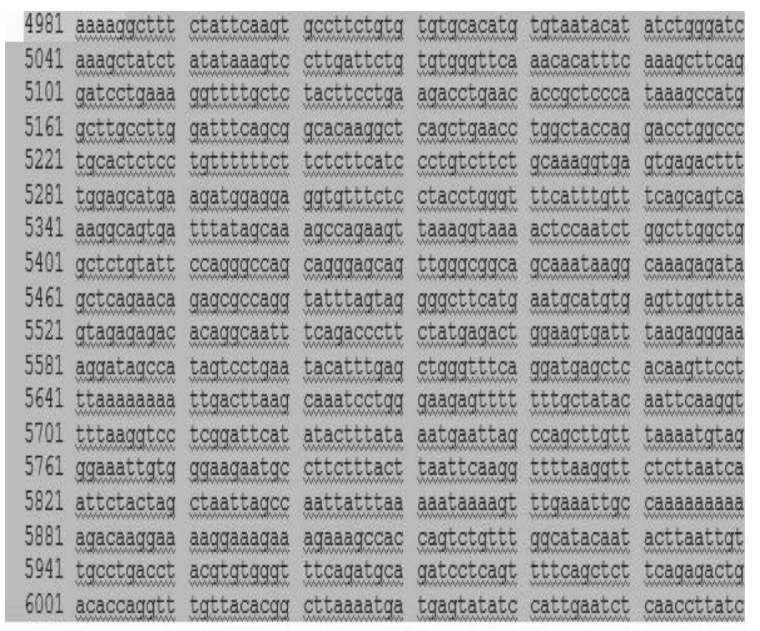

Fig. 2 Sequencing of CTLA4 gene is done by NCBI from website https://www.ncbi.nlm.nih.gov.

Also, by sequencing, none of the cases and controls revealed the presence of the $-318 \mathrm{C} / \mathrm{T}$ polymorphism on the CTLA-4 gene, which agrees with our results of the RFLP PCR (Fig. 3 and Fig. 4).
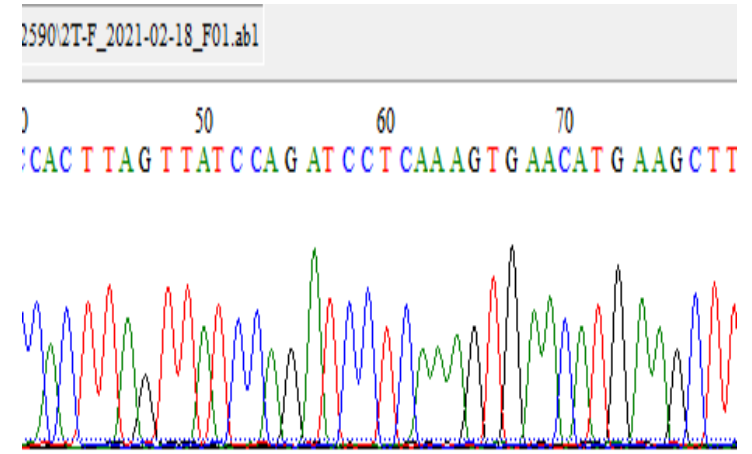

Fig. 3. Example of part of the nucleotide sequence of the CTLA-4 gene not expressing the C / T mutation at position 318 in alloimmunized patient No. 2 .

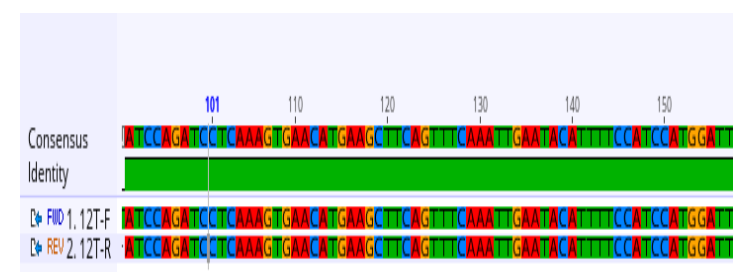

Fig. 4. Example of alignment of Forward and Reverse sequences of the target sequence of the CTLA-4 gene not expressing the $-318 \mathrm{C} / \mathrm{T}$ mutation by the "Genious" software in patient alloimmunized No. 12.

\section{Discussion}

CTLA-4 is expressed constitutively on Treg cells and on T lymphocyte activated and is crucial in preventing $\mathrm{T}$ cell activation and peripheral tolerance and immunological anergy[16]. Ligation of CTLA-4 with its ligands, CD80 or CD86, inhibits the cell cycle and the activity of the transcription factors NF- $\kappa \mathrm{B}, \mathrm{NF}-\mathrm{AT}$, and AP-1 [17]. Hence, any polymorphisms existing in functional sites of CTLA-4 genes may affect her expression and function.

Indeed, several markers of the polymorphism of the upstream CTLA-4 gene (rs5742909, rs11571317, rs16840252 and rs4553808 in the promoter region and rs231775 in exon 1) or in the downstream region (rs3087243) have been reported. It has been suggested that SNP -318C / T (rs5742909) located in the promoter region of the CTLA-4 gene, affects the activity of the promoter and therefore the expression of CTLA-4 at the cell surface. Carriers of the T allele showed marked improvement in the expression of CTLA-4 mRNA and, consequently, greater expression of the CTLA-4 protein on the cell surface [18] .

The CTLA-4 polymorphisms gene were found to be associated with several autoimmune diseases and allograft rejection [15],[19] however To date to our knowledge no studies have explored CTLA-4 variants in transfused thalassemia patients ; So our studies is the first to investigate the association of $-318 \mathrm{C} / \mathrm{T}$ CTLA-4 polymorphism with the alloimmunization occurrence in thalassemia patients.

In our cohort, none of the 35 patients and healthy control revealed this mutation.

However, we are conscious that the limited number of cases, but we can make two hypotheses suggesting that this mutation is not present or is present in our population but at an extremely low frequency. Indeed, the two suggestions revealed that the polymorphism $-318 \mathrm{C} / \mathrm{T}$ of the CTLA4 gene is not associated with the occurrence of post-transfusion alloimmunization among our patients. In accordance with others studies, mutated genotype TT was less common but the results of the effect of $-318 \mathrm{C} / \mathrm{T}$ variant on different diseases are controversial : the results of a only study carried out on a polytransfused SCD (Brazilian) patients by Olivier et al. [20], the $-318 \mathrm{C} / \mathrm{T}$ polymorphism of the CTLA-4 gene was described as associated with post-transfusion alloimmunization in 134 sickle cell patients (Alloimmunized) [20], the homozygous mutated TT genotype was found at $0 \%$, $\mathrm{C} / \mathrm{T}$ at $3 \%$ in non-allo-immunized (253) and $11 \%$ in alloimmunized while the wild-type genotype was predominant between $88 \%$ and $96 \%$ for both groups of patients. On the other hand, in other studies, SNPs $-318 \mathrm{C} / \mathrm{T}$ was not associated with certain pathologies but the frequencies of the mutated $\mathrm{T}$ allele are similar to the study by Oliviera et al. [20] in 101 patients with hyperthyroidism (Iran) [21], in 536 hematopoietic stem cell donors (Spain) [22] and in 300 women at risk of idiopathic miscarriages and 600 healthy controls (USA) [23].

Several reasons could explain these contradictory results. First, the association could be influenced by different genetic, epigenetic, and environmental factors in geographically separated populations. In addition, the differences in the design and selection criteria of the study, such as the different age and the treatments to which the patients are subjected. however taking into account on the one hand, the strong association between autoimmunizations and alloimmunizations which has been clinically proven by Ryder et al. [24], and also by our study done in 2019 [3]; and on the other hand the effect of variants of the CTLA-4 gene on susceptibility to autoimmune diseases, further studies with a higher number of patients and investigation of others variants of CTLA-4 gene are commended. In fact, autoimmunity markers could be adapted to the transfusion strategy and used to predict the development of alloantibodies. 


\section{CONCLUSION}

The polymorphism $-318 \mathrm{C} / \mathrm{T}$ of CTLA4 gene is not associated with RBC alloimmunization among our thalassemia patients. In the course of these preliminary results, an investigation of the other exons of the CTLA-4 gene on a large cohort is recommended. It would be planned to expand this DNA collection from thalassemia patients and their clinical and immunohematological data with those of other patients followed in other hematology centers in Morocco for the constitution of a larger cohort of patients. In fact, it will be necessary to create collaborations with an epidemiological research project exploring the immunomodulatory genes of susceptibility to posttransfusion allo-immunizations. Similarly, it would be interesting to focus on the study of cases of thalassemic families (siblings) predisposed to allo-immunization for the identification of genetic markers of predisposition to alloimmunization.

\section{REFERENCES}

[1] D. Langhi, E. M. A. Ubiali, J. F. C. Marques, M. de A. Verissimo, S. R. Loggetto, A. Silvinato and W. M. Bernardo, "Guidelines on Betathalassemia major - regular blood transfusion therapy: Associação Brasileira de Hematologia," Rev Bras Hematol E Hemoter 2016;38:341-5. https://doi.org/10.1016/j.bjhh.2016.09.003.

[2] M. D. Cappellini, J. B. Porter, V. Viprakasit and A. T. Taher, "A paradigm shift on beta-thalassaemia treatment: How will we manage this old disease with new therapies?" Blood Rev 2018;32:300-11. https://doi.org/10.1016/j.blre.2018.02.001.

[3] S. El Kababi, M. Benajiba, B. El Khalfi, J. Hachim and A. Soukri, "Red blood cell alloimmunizations in beta-thalassemia patients in Casablanca/Morocco: Prevalence and risk factors," Transfus Clin Biol 2019. https://doi.org/10.1016/j.tracli.2019.06.004.

[4] P. Elhence, A. Solanki and A. Verma, "Red Blood Cell Antibodies in Thalassemia Patients in Northern India: Risk Factors and Literature Review," Indian J Hematol Blood Transfus 2014;30:301-8. https://doi.org/10.1007/s12288-013-0311-y.

[5] I. Ben Amor, N. Louati, H. Khemekhem, A. Dhieb, H. Rekik, M. Mdhaffar and J. Gargouri, "Immunisation anti-érythrocytaire dans les hémoglobinopathies: à propos de 84 cas," Transfus Clin Biol 2012;19:345-52. https://doi.org/10.1016/j.tracli.2012.06.006.

[6] A. Matteocci and L. Pierelli, "Red blood cell alloimmunization in sickle cell disease and in thalassaemia: current status, future perspectives and potential role of molecular typing," Vox Sang 2014;106:197-208. https://doi.org/10.1111/vox.12086.

[7] E. Chevet "Thérapeutiques dans la $\beta$-Thalassémie," 2015

[8] E. Angelucci, S. Matthes-Martin, D. Baronciani, F. Bernaudin, S. Bonanomi, M. D. Cappellini and C. Peters, "Hematopoietic stem cell transplantation in thalassemia major and sickle cell disease: indications and management recommendations from an international expert panel," Haematologica 2014;99:811-20. https://doi.org/10.3324/haematol.2013.099747.

[9] S. Achargui, A. Zidouh, S. Abirou, F. Z. Merhfour, S. Monsif Amahrouch S and M. Benajiba, "Identification des allo-anticorps seuls et associés : bilan de trois années au centre régional de transfusion sanguine de Rabat/Maroc et difficultés de prise en charge transfusionnelle," Transfus Clin Biol 2017; 24:422-30. https://doi.org/10.1016/j.tracli.2017.04.006.

[10] N. H. Smith, E. A. Hod, S. L. Spitalnik, J. C. Zimring and J. E. Hendrickson, "Transfusion in the absence of inflammation induces antigen-specific tolerance to murine RBCs," Blood 2012;119:1566-9. https://doi.org/10.1182/blood-2011-09-382655.

[11] S. Sakaguchi, T. Yamaguchi, T. Nomura and M. Ono. "Regulatory T cells and immune tolerance," Cell 2008;133:775-87. https://doi.org/10.1016/j.cell.2008.05.009.

[12] S. Read, V. Malmström and F. Powrie, "Cytotoxic T lymphocyteassociated antigen 4 plays an essential role in the function of $\mathrm{CD} 25(+) \mathrm{CD} 4(+)$ regulatory cells that control intestinal inflammation," $J \quad \operatorname{Exp} \quad$ Med 2000;192:295-302. https://doi.org/10.1084/jem.192.2.295.

[13] F. Eliana, P. Suwondo, A. Asmarinah, A. Harahap, S. Djauzi, J. Prihartono, T. G. D. Pemayun, "The Role of Cytotoxic T-lymphocyte- associated Protein 4 (CTLA-4) Gene, Thyroid Stimulating Hormone Receptor (TSHR) Gene and Regulatory T-cells as Risk Factors for Relapse in Patients with Graves Disease," Acta Medica Indones 2017;49:195-204.

[14] R. Elshazli, A. Settin and A. Salama, "Cytotoxic T lymphocyte associated antigen-4 (CTLA-4) $+49 \mathrm{~A}>\mathrm{G}$ gene polymorphism in Egyptian cases with rheumatoid arthritis," Gene 2015;558:103-7. https://doi.org/10.1016/j.gene.2014.12.046.

[15] J. Hammrich, S. Wittig, T. Ernst and B. Gruhn, "CTLA-4 polymorphisms: influence on transplant-related mortality and survival in children undergoing allogeneic hematopoietic stem cell transplantation," J Cancer Res Clin Oncol 2018;144:587-92. https://doi.org/10.1007/s00432-018-2578-8.

[16] T. L. Walunas, D. J. Lenschow, C. Y. Bakker, P. S. Linsley, G. J. Freeman, J. M. Green and J. A. Bluestone, "CTLA-4 can function as a negative regulator of T cell activation," Immunity 1994;1:405-13. https://doi.org/10.1016/1074-7613(94)90071-x.

[17] E. Valk, C. E. Rudd and H. Schneider, "CTLA-4 trafficking and surface expression," Trends Immunol 2008;29:272-9. https://doi.org/10.1016/j.it.2008.02.011.

[18] A. Ligers, N. Teleshova, T. Masterman, W-X Huang, and J. Hillert, "CTLA-4 gene expression is influenced by promoter and exon 1 polymorphisms," Genes Immun 2001;2:145-52. https://doi.org/10.1038/sj.gene.6363752.

[19] S. Orrù, N. Orrù, E. Manolakos, R. Littera, G. Caocci, G. Giorgiani, and G. La Nasa, "Recipient CTLA-4*CT60-AA genotype is a prognostic factor for acute graft-versus-host disease in hematopoietic stem cell transplantation for thalassemia," Hum Immunol 2012;73:282-6. https://doi.org/10.1016/j.humimm.2011.12.014.

[20] V. B. Oliveira, M. R. Dezan, F. C. A. Gomes, S. F. Menosi Gualandro, J. E. Krieger, A. C. Pereira, et al. $-318 \mathrm{C} / \mathrm{T}$ polymorphism of the CTLA4 gene is an independent risk factor for $\mathrm{RBC}$ alloimmunization among sickle cell disease patients. Int J Immunogenet 2017; 44:219-24. https://doi.org/10.1111/iji.12334.

[21] M. Narooie-Nejad, O. Taji, D. M. Kordi Tamandani, M. A. Kaykhaei, "Association of CTLA-4 gene polymorphisms $-318 \mathrm{C} / \mathrm{T}$ and $+49 \mathrm{~A} / \mathrm{G}$ and Hashimoto's thyroidits in Zahedan, Iran." Biomed Rep 2017;6:108-12. https://doi.org/10.3892/br.2016.813.

[22] A. Pérez-García, R. De la Cámara, J. Román-Gómez, A. JiménezVelasco, M. Encuentra, J. B. Nieto JB and GVHD/Immunotherapy Committee of the Spanish Group of Hematopoietic Stem Cell Transplantation, "CTLA-4 polymorphisms and clinical outcome after allogeneic stem cell transplantation from HLA-identical sibling donors," Blood 2007;110:461-7. https://doi.org/10.1182/blood-200701-069781.

[23] M. K. Misra, A. Mishra, S. R. Phadke, and S. Agrawal, "Association of functional genetic variants of CTLA4 with reduced serum CTLA4 protein levels and increased risk of idiopathic recurrent miscarriages," Fertil Steril 2016;106:1115-1123.e6. https://doi.org/10.1016/j.fertnstert.2016.06.011.

[24] A. B. Ryder, J. E. Hendrickson and C. A. Tormey, "Chronic inflammatory autoimmune disorders are a risk factor for red blood cell alloimmunization," $\mathrm{Br} J$ Haematol 2016;174:483-5. https://doi.org/10.1111/bjh.13781. 